\title{
PENGARUH PEMBERIAN TAPEL PERUT DAN JUS CITRUS AURANTIFOLIA TERHADAP PENURUNAN BERAT BADAN PADA IBU NIFAS
}

\author{
Lina Darmayanti Bainuan ${ }^{1}$; Henny Juaria ${ }^{2}$ \\ ${ }^{1}$ Akademi Kebidanan Griya Husada Surabaya \\ Email : linadarmayanti@gmail.com;telp:08123189108 \\ ${ }^{2}$ Akademi Kebidanan Griya Husada Surabaya \\ Email : hennysugeng@yahoo.com
}

\begin{abstract}
ABSTRAK
Latar Belakang: Selama masa kehamilan terjadi penambahan berat badan karena pembesaran uterus sehingga mengakibatkan perut ibu teregang dan menimbulkan stretchmark. Sebagian besar ibu mengalami kenaikan berat badan yang melebihi batas normal mengalami kesulitan untuk menurunkan berat badannnya setelah melahirkan, perut ibu mengalami kekenduran dan berisiko obesitas di masa mendatang. Tujuan : Penelitian ini bertujuan mengetahui pengaruh pemberian tapel perut dan jus jeruk nipis (Citrus aurantifolia) terhadap penurunan berat badan pada ibu nifas. Metode : Desain penelitian ini adalah quasi eksperimental design, Multiple Group Control. Populasi penelitian adalah seluruh ibu yang melahirkan secara normal di wilayah kerja Puskesmas Balongsari dan Puskesmas Manukan Kulon Surabaya periode April - Juli 2018 Sampel penelitian berjumlah 36, pengambilan dengan teknik sistematic random sampling, yang terdiri kelompok intervensi $1(\mathrm{n}=12)$ responden diberikan tapel perut,kelompok intervensi $2(\mathrm{n}=12)$ diberikan tapel perut dan jus dan kelompok kontrol $(\mathrm{n}=12)$ responden. Analisis menggunakan uji Anova (analisis of variance). Hasil:Temuan menunjukkan Penurunan Berat badan rata-rata pada kelompok intervensi Tapel 3,4 Kg, kelompok intervensi Tapel dan jus C.Aurantifolia 5,07 Kg, dan kelompok kontrol 2,56 Kg. Uji statistik antara kelompok intervensi 1 (Tapel) dengan kelompok kontrol tidak berbeda signifikan $(p=0,804)$, sedangkan antara kelompok kontrol dan intervensi 2 (Tapel+Jus) terdapat perbedaan yang signifikan $(\mathrm{p}=0,006)$. Kesimpulan : Tapel dan jus C.Aurantifolia yang digunakan bersamaan lebih berpengaruh dalam menurunkan berat badan pada ibu nifas dan untuk mengembalikan bentuk tubuhnya serta mencegah terjadinya obesitas dimasa mendatang.
\end{abstract}

Kata Kunci : Tapel perut, Jus C.aurantifolia, berat badan

\begin{abstract}
Background: During pregnancy there is weight gain due to enlargement of the uterus resulting in the mother's stomach stretching and causing stretch marks. Most mothers experience weight gain that exceeds the normal limit having difficulty reducing their weight after giving birth, the mother's stomach becomes slack and at risk of obesity in the future. Objective: This study aimed to determine the effect of giving tapel and lime juice (Citrus aurantifolia) on weight loss in postpartum mothers. Methods: The design of this study was quasi experimental design, Multiple Group Control. The study population was all mothers who gave birth normally in the work area of Balongsari Community Health Center and Manukan Kulon Surabaya Health Center for the April - July 2018 period. The study sample was 36, taken by sistematic random sampling technique, consisting of intervention groups $1(n=12)$ respondents were given a tapel, intervention group $2(n=12)$ were given belly and juice tapes and control group $(n=12)$ respondents. Analysis using the ANOVA test (analysis of variance). Results: Findings showed a decrease in average body weight in the Tapel intervention group $3.4 \mathrm{Kg}$, the Tapel intervention group and C. Aurantifolia juice $5.07 \mathrm{Kg}$, and the control group $2.56 \mathrm{Kg}$. Statistical tests between intervention groups 1 (Tapel) with the control group did not differ significantly $(p=0.804)$, while between the control group and intervention 2 (Tapel + Juice) there were significant differences $(p=0.006)$. Conclusion: Tapel and C.Aurantifolia juice used together are more influential in reducing weight in postpartum mothers and to restore their body shape and prevent obesity in the future.
\end{abstract}

Keywords: Belly Tapel, C.aurantifolia juice, weight 


\section{PENDAHULUAN}

Selama kehamilan seorang wanital mengalami kenaikan berat badan $12-18 \mathrm{Kg}$ bahkan lebih, hingga saat ibu telah bersalin. Setelah melahirkan penurunan berat badannya hanya $\pm 3-5 \mathrm{~kg}$ (Cuningham, 2014).

Selama keamilan kenaikan berat badan ibu merupakan hal yang fisiologis karena adanya janin, plasenta, dan air ketuban di dalam perut ibu. Namun, kenaikan berat badan pada ibu hamil memiliki batas kewajaran dan normalnya kenaikan tergantung dengan indeks masa tubuh (IMT) saat sebelum hamil. (Husin, 2014) Kenaikan berat badan yang melebihi batas normal mengakibatkan sebagian besar ibu mengalami kesulitan untuk menurunkan berat badannya setelah melahirkan.

Penambahan berat badan selama kehamilan merupakan salah satu faktor penentu terjadinya obesitas pada wanita di masa mendatang (Nehring, dkk, 2011). Ibu bersalin banyak mengalami ketidaknyamanan akan penambahan berat badan akibat kehamilannya yang lalu, sehingga melakukan upaya untuk menurunkan berat badan dan mengembalikan bentuk tubuh dengan cara mengkonsunsi jamu dan ramuan lain resep nenek moyang setelah bersalin.

Pada tahun 2008, Badan kesehatan dunia (WHO) mencatat bahwa $68 \%$ penduduk dunia masih menggunakan sistem pengobatan tradisional yang mayoritas melibatkan tumbuhan untuk menyembuhkan penyakit dan lebih dari $80 \%$ menggunakan obat herbal untuk mendukung kesehatan mereka (Saifudin, 2011).
Hasil survei di Amerika Serikat yang dilakukan terhadap 774 wanita dari kelompok menengah ke bawah, diketahui bahwa sepertiga wanita yang sebelum hamil memiliki berat badan normal berubah menjadi obesitas setahun setelah melahirkan (Mamun AA dkk, 2010). Beberapa ahli berpendapat bahwa obesitas yang terjadi setelah melahirkan disebabkan karena pola makan yang tidak terkendali selama masa kehamilan dan juga setelah melahirkan. Hal ini seringkali tidak disadari ibu hamil. Dengan adanya kondisi tersebut pada ibu bersalin, maka beberapa upaya perawatan pada ibu nifas telah dilakukan untuk mengembalikan kondisi tubuh seperti sebelum hamil.

Berdasarkan hasil Penelitian deskriptif yang telah dilakukan dibeberapa daerah di Indonesia, diketahui bahwa ibu setelah melahirkan banyak yang mengkonsumsi jamu dan ramuan lainnya untuk mengembalikan bentuk tubuh atau menurunkan berat badannya setelah melahirkan. (Adela,2014)

\section{BAHAN DAN METODE}

Penelitian ini merupakan penelitian eksperimental dengan desain quasi eksperimental, Multiple Group Control. Subjek penelitian adalah ibu nifas hari ke 3-7 yang melahirkan normal di wilayah kerja puskesmas Balongsari dan Puskesmas Manukan Kulon Surabaya periode April-Juli 2018. Total subjek penelitian berjumlah 36 orang terdiri dari 2 kelompok intervensi dan 1 kelompok kontrol, dengan masing-masing kelompok 12 orang dengan tehnik pengambilan sampel adalah systematic random sampling. Kelompok 
Intervensi I dilakukan perawatan ibu nifas dengan tapel perut (Citrus aurantifolia, limestone dan cajuput oil), kelompok intervensi II di lakukan perawatan ibu nifas dengan tapel dan jus citrus aurantifolia,sedangkan kelompok III adalah kelompok kontrol yang dilakukan perawatan nifas konvensional.

Diawal semua subjek penelitian akan diukur berat badan (BB) nya, kemudian pada kelompok intervensi I akan diberikan tapel perut selama 40 hari, kelompok intervensi II akan diberikan tapel perut dan jus jeruk nipis (Citrus aurantifolia) selama 40 hari, sedangkan kelompok kontrol tidak diberikan, , kemudian hari ke-40 subjek penelitian akan diukur kembali berat badannya kembali. .Penggunaan objek penelitian Tapel Perut akan dioleskan pada perut ibu kemudian dipasangkan gurita atau stagen/bengkung dan jus jeruk nipis (Citrus aurantifolia) diminum oleh ibu bersalin dengan dicampur madu. Pengumpulan data dilakukan dengan menggunakan metode observasi dan pengukuran perubahan berat badan ibu nifas. Selanjutnya dilakukan pengelolaan data secara bivariat menggunakan uji anova (analisis of variance).

\section{HASIL PENELITIAN}

Distribusi frekuensi umur subjek penelitian ibu nifas di wilayah kerja puskesmas Manukan Kulon dan Balongsari periode AprilJuni 2018 manunjukkan bahwa mayoritas umur 26-30 tahun sebanyak 12 orang (33,3\%). Hasil selengkapnya pada tabel 1 berikut ini,
Tabel 1 Distribusi Frekuensi Umur Ibu Nifas di Wilayah Kerja Puskesmas Manukan Kulon dan Balongsari 2018

\begin{tabular}{ccc}
\hline Umur (th) & Frekuensi (f) & \% \\
\hline$<16$ & 4 & 11,1 \\
$16-25$ & 9 & 25 \\
$26-30$ & 12 & 33,3 \\
$31-35$ & 9 & 25 \\
$>35$ & 2 & 5,6 \\
\hline Total & 36 & 100 \\
\hline
\end{tabular}

Selanjutnya data paritas subjek Penelitian pada tabel 2 berikut ini :

Tabel 2 Distribusi Frekuensi Paritas Ibu Nifas di Wilayah Kerja Puskesmas Manukan Kulon dan Balongsari 2018

\begin{tabular}{lcc}
\hline \multicolumn{1}{c}{ Paritas } & $\begin{array}{c}\text { Frekuensi } \\
\text { (f) }\end{array}$ & $\mathbf{( \% )}$ \\
\hline Primipara & 15 & 41,7 \\
Multipara & 21 & 58,3 \\
\hline Total & 36 & 100 \\
\hline
\end{tabular}

Berdasarkan tabel 2 diketahui bahwa mayoritas paritas ibu nifas yang terlibat sebagai subjek Penelitian adalah multipara sebanyak 21 orang $(58,3 \%)$.

Selanjutnya data tentang pola makan ibu nifas di wilayah kerja puskesmas Manukan Kulon dan Balongsari Surabaya.

Tabel 3 Distribusi Frekuensi Pola Makan Ibu Nifas di Wilayah Kerja Puskesmas Manukan Kulon dan Balongsari 2018

\begin{tabular}{ccc}
\hline $\begin{array}{c}\text { Frekuensi Pola } \\
\text { Makan sehari }\end{array}$ & $\begin{array}{c}\text { Frekuensi } \\
\text { (f) }\end{array}$ & $\mathbf{( \% )}$ \\
\hline 2 kali & 1 & 2,8 \\
3 kali & 28 & 77,8 \\
4 kali & 7 & 19,4 \\
\hline Total & 36 & 100 \\
\hline
\end{tabular}

Berdasarkan tabel 3 menunjukkan bahwa mayoritas frekuensi pola makan ibu nifas 3 kali sehari sebanyak 28 orang (77,8\%). 
Tabel selanjutnya menampilkan hasil analisis pengaruh tapel perut dan jus jeruk nipis terhadap penurunan berat badan ibu nifas.

Tabel 4 Analisis Pengaruh Tapel dan Jus Jeruk Nipis Terhadap Berat Badan Ibu Nifas

\begin{tabular}{|c|c|c|c|c|c|}
\hline & Mean & SD & $\begin{array}{c}\text { Selisi } \\
\mathbf{h}\end{array}$ & $\begin{array}{c}95 \% \\
\text { CI }\end{array}$ & $\begin{array}{c}\text { Nila } \\
\text { i p }\end{array}$ \\
\hline $\begin{array}{l}\text { BB } \\
\text { sebelum } \\
\text { pemberi } \\
\text { an tapel } \\
(n=12)\end{array}$ & 53,86 & $\begin{array}{l}8,8 \\
9\end{array}$ & 2,41 & $\begin{array}{l}1,52- \\
3,29\end{array}$ & \\
\hline $\begin{array}{l}\text { BB } \\
\text { sesudah } \\
40 \text { hari } \\
\text { pemberi } \\
\text { an tapel } \\
(n=12)\end{array}$ & $\begin{array}{l}50,37 \\
(3,4)\end{array}$ & $\begin{array}{l}8,0 \\
9\end{array}$ & 1,37 & $\begin{array}{l}2,53- \\
4,27\end{array}$ & $\begin{array}{l}0,80 \\
4\end{array}$ \\
\hline $\begin{array}{l}\text { BB } \\
\text { sebelum } \\
\text { pemberi } \\
\text { an } \\
\text { tapel+ju } \\
\text { s jeruk } \\
\text { nipis } \\
(n=12)\end{array}$ & 63,07 & $\begin{array}{l}9,8 \\
6\end{array}$ & 2,14 & $\begin{array}{l}1,44- \\
2,83\end{array}$ & \\
\hline $\begin{array}{l}\text { BB } \\
\text { sesudah } \\
40 \text { hari } \\
\text { pemberi } \\
\text { an } \\
\text { tapel+ju } \\
\text { s jeruk } \\
\text { nipis } \\
(n=12)\end{array}$ & $\begin{array}{l}58,00 \\
(5,07)\end{array}$ & $\begin{array}{l}9,1 \\
9\end{array}$ & 2,21 & $\begin{array}{l}3,66- \\
6,48\end{array}$ & $\begin{array}{l}0,06 \\
0\end{array}$ \\
\hline $\begin{array}{l}\text { BB awal } \\
\text { masa } \\
\text { nifas } \\
(n=12)\end{array}$ & 63,34 & $\begin{array}{l}11, \\
35\end{array}$ & 1,42 & $\begin{array}{l}0,51- \\
2,34\end{array}$ & \\
\hline $\begin{array}{l}\text { BB } \\
\text { sesudah } \\
\mathbf{4 0} \text { hari } \\
\text { masa } \\
\text { nifas } \\
(n=12)\end{array}$ & $\begin{array}{l}60,87 \\
(2,56)\end{array}$ & $\begin{array}{l}10, \\
1\end{array}$ & 1,80 & $\begin{array}{l}1,42- \\
3,71\end{array}$ & \\
\hline
\end{tabular}

Berdasarkan tabel 4 menunjukkan bahwa rata-rata penurunan $\mathrm{BB}$ pada kelompok Tapel adalah $3,4 \mathrm{Kg} \pm 1,37$, kelompok Tapel+Jus adalah $5,07 \mathrm{Kg} \pm 2,21$ dan pada kelompok kontrol 2,56 $\pm 1,80$. Jika dilihat dari rata-rata tersebut terlihat bahwa berbeda antara Intervensi 1 (Tapel) dengan kontrol dan juga berbeda antara kelompok intervensi 2 dengan kontrol. Akan tetapi jika diuji secara statistik diperoleh hasil bahwa kelompok intervensi 1 dengan kelompok kontrol tidak berbeda signifikan dengan $\mathrm{p}=0,804$, sedangkan antara kelompok Intervensi 2 dengan kelompok kontrol terdapat perbedaan yang signifikan dengan $\mathrm{p}=0,006$.

\section{PEMBAHASAN}

Masa Nifas adalah masa pulihnya kembali alat-lat kandungan dan dan sistem tubuh lainnya seperti sebelum hamil. Perhatian kesehatan pada masa nifas ini sangat diperlukan, untuk menghindari terjadinya komplikasi seperti perdarahan, infeksi dan lainnya seperti penurunan berat badan (Siti Saleha,2009).

Berdasarkan hasil Penelitian karakteristik ibu nifas yang menjadi responden mayoritas berumur 26-30 tahun $(33,3 \%)$ dan mayoritas dengan paritas multipara $(58,3 \%)$. Usia dan paritas ibu juga berpengaruh pada pengetahuan cara perawatan diri selama masa nifas.

Berdasarkan hasil Penelitian menujunjukkan bahwa dengan pemberian tapel saja dan pemberian tapel jus jeruk nipis, ibu dengan perawatan konvensional juga mengalami penurunan berat badan, meski begitu efeknya paling kecil yaitu 2,47 kg. Seorang wanita setelah melahirkan akan kehilangan berat badannya 5 sampai $6 \mathrm{~kg}$ setelah hasil konsepsi (bayi dan plasenta) lahir dan pengeluran darah normal, dan biasanya penurunan lebih lanjut berat badan sebanyak 2- 
$3 \mathrm{~kg}$ melalui diuresis.(Zanotti,2015) Sebagian besar wanita mendekati berat badan sebelum hamil dalam waktu 6 bulan setelah melahirkan, namun masih memiliki surplus 1,4 kg.(Cuningham,2014 \& Gore SA,2003).

Berdasarkan tabel 3 menunjukkan bahwa sebagian besar ibu nifas pola makannya sebanyak 3 kali sehari $(77,8 \%)$. Kondisi ini masih wajar dan diperlukan untuk memenuhi kebutuhan gizi ibu dan bayi agar membantu proses pemulihan tubuh ibu dan produksi ASI. Dengan kebiasaan pola makan yang tidak berlebihan tersebut akan menujang dalam menjaga berat badan ibu yang tidak berlebihan.

Tapel perut yang digunakan pada Penelitian ini merupakan kombinasi dari Citrus aurantifolia, limestone dan cajuput oil, memiliki kandungan yang bermanfaat terhadap penurunan berat badan. Citrus aurantifolia atau jeruk nipis mengandung tinggi vitamin $\mathrm{C}$ dan flavonoid hesperidin yang mampu menaikkan kadar kolesterol HDL.(Perpustakaan Negara Malaysia,2001, JH Kim et al,2005).

Seperti hal nya Penelitian yang telah dilakukan, pemberian minyak esensial jeruk nipis (Citrus aurantifolia) menunjukkan penurunan berat badan dan konsumsi makanan pada tikus. Limonene dalam jeruk nipis tersebut memainkan peran penting dalam penurunan berat badan dan dapat berguna dalam pengobatan obesitas (Ajugwo,A.O,2012)

Limestone atau kapur sirih mengandung tinggi kalsium. Limestone apabila diberi sedikit air akan menghasilkan panas (JH Kim et al,2005). Pemberian diet tinggi kalsium 1,6\% (di atas angka kecukupan gizi yang dianjurkan) pada tikus dapat menurunkan berat badan sebesar 30,95 $\pm 2,05 \mathrm{gr}$ (Zamel MB,2005). Kalsium berperan mengatur metabolisme lemak adiposit dan simpanan triasilgliserol. Konsumsi kalsium yang tinggi meningkatkan ion kalsium plasma yang menyebabkan penurunan kalsium di intrasellular. Penurunan ini menghambat sintesis asam lemak dan mendorong lipolisis pada jaringan adiposa dan dipecah menjadi asam lemak dan gliserol. Asam lemak masuk ke dalam darah sebagai asam lemak bebas dan dioksidasi menjadi $\mathrm{CO}_{2}$. Hal ini yang menyebabkan penurunan berat badan (Zamel MB,2005).

Minyak kayu putih atau oleum melaleuca cajeputi mengandung limonene sebanyak $10 \%$. Nutrisi yang paling menonjol dalam minyak kayu putih adalah 1,8 cineole, juga dikenal sebagai eucalyptol sebagai analgesik. Astringent pada minyak kayu putih mampu mengecilkan pori-pori kulit dan menghilangkan kelebihan minyak. ${ }^{11}$

Kelompok intervensi 2 diberi tapel pada perutnya dan ditutup dengan stagen serta mengonsumsi jus jeruk nipis selama \pm 35 hari dengan takaran jus yaitu $0,5-1 \mathrm{cc} / \mathrm{kg}$ BB atau 1 buah jeruk nipis dengan diameter $5 \mathrm{~cm}$. Pemberian kombinasi tapel dan jus jeruk nipis mempercepat penurunan berat badan dibandingkan dengan pemberian tapel saja. Hal ini dikarenakan, selain efek tapel perut terdapat efek jus jeruk nipis yang dalam $100 \mathrm{mg}$ mengandung vitamin $\mathrm{C}$ sebanyak $63 \mathrm{mg}$ dan hesperidin, yang mana dapat membantu menurunkan kadar kolesterol total (tandi Herbi,2015). Penelitian serupa menunjukkan 
bahwa pemberian jus jeruk sebanyak $750 \mathrm{ml}$ per hari dapat memengaruhi profil lipid yaitu meningkatkan kolesterol HDL sebanyak 21\% pada subjek dyslipidemia (Solmaz,2010) .

\section{SIMPULAN DAN SARAN}

Penggunaan tapel dan mengkonsumsi jus C.Aurantifolia memiliki efek yang lebih menguntungkan bagi ibu setelah melahirkan untuk membantu mengembalikan bentuk tubuh melalui penurunan berat badan. Selama penggunaan tapel dan atau jus C.Aurantifolia ini tidak didapatkan efek yang merugikan baik bagi ibu maupun bagi bayi. Hal yang perlu diperhatikan adalah perlunya kedisiplinan dalam pengunaan tapel dan jus jeruk nipis oleh ibu setelah melahirkan untuk mendapatkan hasil yang maksimal.

\section{KEPUSTAKAAN}

1. Adela Mentari. 2014. Kajian Hubungan Komposisi dan Khasiat Ramuan Obat Tradisional yang Digunakan oleh ibu-ibu pada Masa Nifas di Kabupaten Sleman Bagian Barat. Skripsi Fak.Farmasi UGM Yogyakarta.

2. Ajugwo A.O et al. Nutritional Value of Lime and Lemon in Hypercholesterolaemic Induced Rats. Asian Journal of Medical Science;2012:13-16

3. Bostham M,Asgary S,Mostaghian J,Naderi G, Jafari-Dinani N. Impact of Fresh Lime and Peel on Atherosclerosis Progression in An Animal Model. Arya Artheroscler.2012;9(6):357-62

4. Cunningham G. F., Kenneth J., Leveno Steven L., Bloom Catherine Y., Spong Jodi
S., Dashe Barbara L., Hoffman Brian M., Casey Jeanne S., Sheffield., 2014. William Obstetrics 24th edition.hal. 668-671. USA: McGraw-Hill.

5. Department of Human Services Environmental Toxicology Section Office of Environmental Public Health, 1998. Technical Bulletin Health Effects Information: Calcium Carbonat "lime, limewater". Portland

6. Gore SA,Brown DM, Westi DS. The role of postpartum weight retention in obesity among woman: a review of the evidence. Ann Behav Med.2003;26(2):149-59

7. Husin,F. 2014. Asuhan Kebidanan Kehamilan Berbasis Bukti. Jakarta: Sagung Seto

8. Mamun AA, Kinarivala M, O'Callaghan MJ, Williams GM, Najman JM, Callaway LK. Associations of excess weight gain during pregnancy with long-term maternal overweight and obesity: evidence from 21 $y$ postpartum follow-up. Am J Clin Nutr. 2010;91:1336-41.

9. Nehring I, Schmoll S, Beyerlein A, Hauner H, Von Kries R. Gestational weight gain and long-term postpartum weight retention: a meta-analysis. Am J Clin Nutr. 2011;94:1225-31

10. Perpustakaan Negara Malaysia, 2001.Kapur.http://www.pnm.gov.my/sirih pinang/sp-kapur.htm diakses pada tanggal 1 Juni 2017 pukul 20.05 WIB

11. J.H. Kim et. Al. Essential Leaf Oils from Melaleuca cajuputi.Proc. WOCMAP III, Vol.6: Traditional Medicine \& 
Nutraceuticals Eds. U.R. Palaniswamy, L.E. Craker and Z.E. Gardner Acta Hort. 680, ISHS 2005

12. Saifudin, 2011. Standarisasi Bahan Obat Alam. Yogyakarta: Graha Ilmu.

13. Siti Saleha. 2009. Asuhan Kebidanan Pada Masa Nifas. Jakarta: Salemba Medika.

14. Tandi Herbie, 2015. Kitab 226 Tumbuhan Obat Untuk Penyembuhan Penyakit dan Kebugaran Tubuh. Yogyakarta: Octopus Publishing House.
15. Zanotti J,Capp E., Wender MC. Factor associated with postpartum weight retention in a Bazillian cohort.Rev Bras Ginecol Obstet.2015;37(4):167-71

16. Zemel MB, dkk. Regulation of Adiposity and Obesity Risk by Dietary Calcium: Mechanisms and Implications. 2005. Journal of the American of Nutrition. Online, Vol.21, No.2, http://www.jacn.org, 